\title{
Predictive Elastoplastic Damage Constitutive Law: Establishment of Equivalence Relation between Intrinsic and Extrinsic Material Parameters
}

\author{
Mohamed-Ali Rezgui ${ }^{*}$, Mohamed-Toumi Nasri², Mahfoudh Ayadi ${ }^{2}$ \\ ${ }^{1}$ UR-MSSDT (99-UR11-46), Ecole Nationale Supérieure d'Ingénieurs de Tunis, ENSIT, University of Tunis, Tunis, Tunisia \\ ${ }^{2}$ Department of Mechanical Engineering, Ecole Nationale d'Ingénieurs de Bizerte, ENIB, University of Cartage, Bizerte, Tunisia \\ Email: ^mohamedali.rezgui@esstt.rnu.tn, ^mohamedali.rezgui@gmail.com
}

How to cite this paper: Rezgui, M.-A., Nasri, M.-T. and Ayadi, M. (2016) Predictive Elastoplastic Damage Constitutive Law: Establishment of Equivalence Relation between Intrinsic and Extrinsic Material $\mathrm{Pa}$ rameters. Materials Sciences and Applications, 7, 730-753.

http://dx.doi.org/10.4236/msa.2016.711058

Received: September 26, 2016 Accepted: November 12, 2016

Published: November 15, 2016

Copyright $\odot 2016$ by authors and Scientific Research Publishing Inc. This work is licensed under the Creative Commons Attribution International License (CC BY 4.0).

http://creativecommons.org/licenses/by/4.0/ (c) (i) Open Access

\begin{abstract}
The purpose of the current work is the development and application of a new identification method of material parameters of elastoplastic damage constitutive model under large strains. A relationship relating the intrinsic and extrinsic parameters of a reference material is built and transformed in equivalence relation. Extrinsic parameters concern the shape of their experimental tensile force/elongation curve, however, intrinsic parameters deal with Swift hardening law coupled with an isotropic damage variable. The relationship is carried out from a statistical characterization of a material reference (standard-steel E24). It based on multiple linear regression of a data set obtained according to a full factor design of numerical simulations of mechanical tensile tests. All materials satisfying this equivalence relation belong to the same equivalence class. This is motivated by observing that gathered materials must behave somewhat like the reference material. The material parameters can be immediately identified by only one task by running the found relationship. The current method facilitates the identification procedure and offers a substantial savings in CPU time. However it just needs only one simulation for the identification of similar behavior instead of the few hundred required when using other methods.
\end{abstract}

\section{Keywords}

Characterization, Parameter Identification, Tensile Tests, Standard-Steel E24, Elastoplastic Damage Constitutive Law, Equivalence Class

\section{Introduction}

The optimization of the forming process by plastic deformation leads to cost savings in 
manufacturing and improvement of the reliability of the formed parts. Numerical simulation of the mechanical behavior of thin shells is used as tool to predict and evaluate the risks and failures that maybe encountered in the forming process [1] [2].

The material constitutive law must be able to capture anisotropy, strain hardening, damage evolution and forming limits. Continuum models for hardening plasticity coupled with damage help designers to evaluate manufacturability in the early design stage for mechanical parts production. Most of these models are based on a macroscopic consideration whose formulation is defined within the framework of irreversible thermodynamic processes [3] based on state variables associated with the phenomena under consideration.

Two modeling approaches are currently available in literature for the damage assessment. The first approach is based on the void growth rate inside a phase with elastoplastic behavior [4] [5]. In this approach damage is represented by a scalar representing the void volume fraction; its evolution is linked to the growth of the voids in the material. This evolution occurs in three stages: nucleation of microvoids or microcracks, then coalescence of microcracks into macrocracks and finally crack growth which leads to final failure [6] [7]. In the second approach, a damage variable defined as the relative reduction of the transverse section of an elementary representative volume element is used [8] [9]. This definition for damage allows for the introduction of effective stresses using equivalence principles [10] either by using the equivalent strain energy [4] [5] [11] or the equivalent strain [6] [7]. The principle of equivalent strain states that the strain in the nominal and effective configuration must be the same; whereas the principle of equivalent strain energy states that the elastic strain energy densities are the same for the effective and nominal configurations. In both approaches, damage is defined analytically using constitutive laws able to model the forming process and predict the localized zones of failure [12] [13] [14] [15] [16].

The development of different procedures for the characterization of constitutive laws of materials through the use of the finite element method [17] [18] [19] was instrumental in the identification of nonlinear constitutive laws with a large number of parameters. The usual continuum mechanics problem consists in determining the parameters of the material model; analytical solutions to such a problem are virtually inexistent except in very special cases. Nevertheless, the identification of parameters of a constitutive law is often treated as an inverse problem. Genetic algorithms and neural networks were used for parameter identification of nonlinear models [20] [21] [22]. The simplex method was used to determine parameters associated with anisotropy of materials in linear problems [23] [24].

In some cases a combination of methods were used to reach an optimal solution. For the most of these methods, the material parameters were obtained iteratively by minimizing an objective error function involving the constitutive law. The objective function is an expression of the deviation between experimental results and their counterparts obtained through the finite element method [25] [26]; this objective function may be defined as the square error between the experimental and numerical values at the 
same points for fields such as elongation and stress [19] [27] etc.

Parameter identification methods available in the literature are based on complex algorithms and time consuming calculation. In most optimization procedures, the uniqueness of the optimal solution is not guaranteed and this may be reflected in the dependence of the optimal solution on the initial guess for the parameters. Furthermore, additional constraints must be added in order to take into account certain physical phenomena that are mathematically impossible to uncouple. Given the complexity of these methods and the size of the experimental data, appropriate computing strategies are necessary.

To the authors' best knowledge there is no method in the literature which would be able to identify material parameters easily and quickly. The aim of this paper is to present a new procedure of identifying material model parameters. It deals with establishing a linear relationship between material parameters and shape indexes extracted from the experimental force/elongation (tensile test) curves. This study is limited to the Swift hardening law coupled with an isotropic damage variable.

The idea is to gather materials having an equivalent behavior in the same class according to the shape of their experimental tensile force/elongation response. This is motivated by observing that gathered materials must behave somewhat like a reference material. An equivalence relation is built from a statistical characterization of a material reference and then extends to other materials belonging to this class. The equivalence relation relates the material parameters and shape indexes of experimental tensile force/ elongation curve.

\section{Theoretical Development}

\subsection{Constitutive Laws}

In a previous study [28] [29], an isotropic damage law $D$ was proposed based on the notion of effective stress and apparent stress, an anisotropy using the Hill48 yield criterion and Swift's isotropic hardening law coupled with the damage variable $D$. The equivalent stress and damage are given as:

1) Hill's equivalent stress $\sigma_{e q}$ de Hill48 as a function of the anisotropy parameters $(F$, $G, H, N)$ of the in-plane stresses $\sigma_{1}, \sigma_{2}$ and $\sigma_{12}$ :

$$
\sigma_{e q}=\sqrt{F \sigma_{2}^{2}+G \sigma_{1}^{2}+H\left(\sigma_{2}-\sigma_{1}\right)^{2}+2 N \sigma_{12}^{2}}
$$

2) The damage $D$ as a function of the cumulative equivalent plastic strain $\varepsilon_{e q}$ :

$$
D=\left[\frac{\varepsilon_{e q}+\varepsilon_{s}}{\varepsilon_{u}}\right]^{\gamma}
$$

where: $D$ is the damage variable specified as $0 \leq D \leq 1 ; D=0$ (initial undamaged state), $D=1$ (final fractured state); $\varepsilon_{u}$ is the total cumulated plastic strain up to failure; $\varepsilon_{s}$ is a threshold strain level under which no damage is incurred; $\gamma$ is an exponent that indicates the extent of damage in the material.

3) Swift's isotropic hardening law coupled with damage expresses the equivalent 
stress as a function of the equivalent strain through the Equation (3).

$$
\sigma_{e q}=K[1-D]\left(\varepsilon_{0}+\varepsilon_{e q}\right)^{n}
$$

In order to characterize the material law three sets of unknowns must be determined:

1) Four anisotropy parameters $\mathrm{F}, \mathrm{G}, \mathrm{H}$ and $\mathrm{N}$ in terms of the Lankford coefficients $\left(r_{0}\right.$, $r_{45}$ and $r_{90}$ ) are evaluated experimentally [28].

2) Three parameters from Swift's hardening law $\left(K, \varepsilon_{0}, n\right)$ where the equivalent yield stress is given in terms of the cumulated equivalent plastic strain as:

$$
\sigma_{Y}=K\left(\varepsilon_{0}+\varepsilon_{e q}\right)^{n}
$$

3) Three parameters to identify the isotropic ductile damage law $\gamma, \varepsilon_{s}$ and $\varepsilon_{u r}$.

In this study an original method to identify the last two sets of parameters for hardening and damage is presented.

\subsection{Identification Procedure}

A procedure of identification by multiple regression is executed in three steps. In the first step data are collected according to a full factorial design. The independent variables consist in virtual material parameters of the constitutive law. Ultimately these material parameters are the target of the identification procedure. For each set of the virtual material parameters, the constitutive law is defined and then implemented in ABAQUS/Standard to simulate a characterization test. The dependent variables are represented by a set of shape indexes extracted from the simulated characterization tests.

In the second step, it comes to establish a relationship by multiple linear regression between material parameters and shape indexes. In fact, multiple regression provides a means to express a dependent variable $(z)$ in terms of $f$ independent variables $\left(x_{1}, x_{2}, \cdots, x_{f}\right)$ :

$$
z=\alpha_{0}+\alpha_{1} x_{1}+\alpha_{2} x_{2}+\cdots+\alpha_{f} x_{f}+e_{z}
$$

where $\alpha_{0}, \alpha_{1}, \alpha_{2}, \cdots$ are the regression coefficients with residual error $e_{z^{*}}$

In the present study we are interested in the transposed problem stated as follows; given $p$ dependent variables $\left(z_{1}, z_{2}, \cdots, z_{p}\right)$ and $f$ independent variables $\left(x_{1}, x_{2}, \cdots, x_{f}\right)$. For the $i^{\text {th }}$ variable $x_{i}$ multiple linear regression leads to a linear equation of the form $x_{i}=g_{i}\left(z_{1}, z_{2}, \cdots, z_{p}\right)$ :

$$
x_{i}=a_{i 0}+a_{i 1} z_{1}+a_{i 2} z_{2}+\cdots+a_{i p} z_{p}+e_{i}
$$

This generates a system of $f$ linear equations that can be written in a standard matrix form:

$$
\{X\}^{*}=[A]^{*}\{Z\}+\{\xi\}
$$

$\{X\}^{*}$ is the unknown vector of the material parameters (independent variables) to be calculated, $[A]^{*}$ is the regression coefficient matrix, $\{Z\}$ is the vector of the shape indexes (dependent variables) and $\{\xi\}$ is the residual vector. 


$$
\begin{aligned}
& \{X\}^{*}=\left(\begin{array}{c}
x_{1} \\
\vdots \\
x_{i} \\
\vdots \\
x_{f}
\end{array}\right)_{(f \times 1)} ;[A]^{*}=\left[\begin{array}{ccccc}
a_{10} & \cdots & a_{1 j} & \cdots & a_{1 p} \\
\vdots & & \vdots & & \vdots \\
a_{i 0} & \cdots & a_{i j} & \cdots & a_{i p} \\
\vdots & & \vdots & & \vdots \\
a_{f 0} & \cdots & a_{f j} & \cdots & a_{f p}
\end{array}\right]_{(f \times(p+1))} ; \\
& \{Z\}=\left(\begin{array}{c}
1 \\
\vdots \\
z_{j} \\
\vdots \\
z_{p}
\end{array}\right)_{((p+1) \times 1)} ;\{\xi\}=\left(\begin{array}{c}
e_{1} \\
\vdots \\
e_{i} \\
\vdots \\
e_{f}
\end{array}\right)_{(f \times 1)}
\end{aligned}
$$

The criteria for the minimization of the residual vector $\{\xi\}$ of the predictive correlations of relation (Equation (7)) is imposed by the hypothesis test of the analysis of variance (ANOVA) such as the coefficient of determination $\left(R^{2}\right)$, the adjusted coefficient of determination $\left(R_{a d j}^{2}\right)$ and the root mean square error (RMSE). Finally the adjusted value $\{X\}$ is obtained using Equation (8) with $\left\{\xi_{r}\right\}$ the residual between predicted and observed values (9).

$$
\begin{aligned}
\{X\} & =[A]\{Z\} \\
\left\{\xi_{r}\right\} & =\{X\}^{*}-\{X\}
\end{aligned}
$$

In the third step the material parameters are identified by substituting in the established relation (Equation (8)) the shape indexes extracted from the experimental tensile curves of a reference material.

The accuracy of the identified model is estimated by minimizing the objective functions [30] $\xi_{F}$ and $\xi_{U}$, which expresses the discrepancy between the experimentally measured and the numerically computed force and elongation for a set of $m$ points. The average relative errors for the force and elongation from the tensile tests are provided by the Equations (10) and (11) respectively.

$$
\begin{aligned}
& \xi_{F}=\frac{1}{m} \sqrt{\sum_{i=1}^{m}\left(\frac{F_{\text {exp }}^{i}-F_{\text {num }}^{i}}{F_{\text {exp }}^{i}}\right)^{2}} \\
& \xi_{U}=\frac{1}{m} \sqrt{\sum_{i=1}^{m}\left(\frac{U_{\text {exp }}^{i}-U_{\text {num }}^{i}}{U_{\text {exp }}^{i}}\right)^{2}}
\end{aligned}
$$

where, $F_{\text {iexp }}$ and $F_{\text {inum }}$ are respectively the experimental and calculated tensile force. $U_{\text {iexp }}$ and $U_{\text {inum }}$ are respectively, the experimental and the calculated elongations and $\mathrm{m}$ is the total number of experimental points.

\subsection{Equivalence Relation and Equivalence Class}

Once the identification of the material parameters is successful for the reference material, the relation (12) of the regression coefficent matrix derived from relaion (8) can be 
written as:

$$
\{X\}\left\{Z_{x}\right\}^{\mathrm{T}}\left(\left\{Z_{x}\right\}\left\{Z_{x}\right\}^{\mathrm{T}}\right)^{-1}=[A]
$$

where the couple $\left(\{X\},\left\{Z_{x}\right\}\right)$ represents respectively the material parameters and the experimental shape indexes of the reference material; than the "equivalence relation $(R)$ " over the set $\mathbb{R}^{f} \times \mathbb{R}^{p+1}$ ( $\mathbb{R}$ is the set of real numbers) is built between two couples of characteritics as:

$$
\left(\{X\},\left\{Z_{x}\right\}\right) R\left(\{Y\},\left\{Z_{y}\right\}\right)
$$

where $\left(\{Y\},\left\{Z_{y}\right\}\right)$ represents respectively the material parameters and the experimental shape indexes of a new material. The relationship (13) can be expressed as:

$$
[A]=\{X\}\left\{Z_{x}\right\}^{\mathrm{T}}\left(\left\{Z_{x}\right\}\left\{Z_{x}\right\}^{\mathrm{T}}\right)^{-1}=\{Y\}\left\{Z_{y}\right\}^{\mathrm{T}}\left(\left\{Z_{y}\right\}\left\{Z_{y}\right\}^{\mathrm{T}}\right)^{-1}
$$

It is easy to prove that the equality relation $R$ satisfies: the reflexive, symmetric, and transitive properties. The set $\{S\}$ is "an equivalence class".

$$
\{S\}=\left\{\left(\{Y\},\left\{Z_{y}\right\}\right) \in \mathbb{R}^{f} \times \mathbb{R}^{p+1} \mid\left(\{X\},\left\{Z_{x}\right\}\right) R\left(\{Y\},\left\{Z_{y}\right\}\right)\right\}
$$

So the reference material characterizes by $\left(\{X\},\left\{Z_{x}\right\}\right)$ is considred as a equivalence class. Thereby any other new material, that belongs to this equivalence class shares the same attributes. This is motivated by its behavior that must be similar to that of the reference material. The material parameters verctor $\{Y\}$ is immediately calculated by the relationships (8). This must be true regardless of the experimental conditions (speed, temperature) of the tensile test.

\subsection{Shape Indexes of the Tensile Test Curves}

The shape indexes vector $\{Z\}$ is constituted by the specific points characterizing the tensile force/elongation curve (Figure 1).

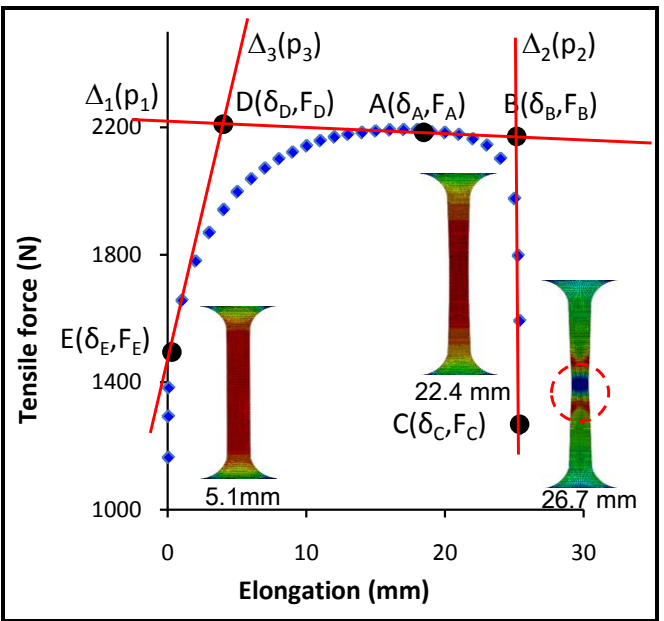

Figure 1. Shape indexes of the tensile force/elongation curve. 
The points $\mathrm{A}\left(\delta_{A}, F_{A}\right)$ and $\mathrm{C}\left(\delta_{C} F_{C}\right)$ correspond, respectively, to the maximum force, the maximum elongation. $\mathrm{E}\left(\delta_{E}, F_{E}\right)$ corresponds to the minimum force of the hardening area on the tensile force/elongation curve. After selecting $\Delta_{1}, \Delta_{2}$ and $\Delta_{3}$ are tangent lines to the tensile force/elongation curve that pass through the selected points $\mathrm{A}, \mathrm{C}$ and $\mathrm{E}$. These three tangent lines are plotted on excel to show the bell shaped tensile curve. $\mathrm{B}\left(\delta_{B}\right.$, $\left.F_{B}\right)$ and $\mathrm{D}\left(\delta_{D}, F_{D}\right)$ are the intersection points of the tangent lines $\Delta_{1}$ with $\Delta_{2}$ and $\Delta_{1}$ with $\Delta_{3}$, respectively. The indexes $p_{1}\left(\Delta_{1}\right), p_{2}\left(\Delta_{2}\right)$ and $p_{3}\left(\Delta_{3}\right)$ are the respective slopes of the tangent lines $\Delta_{1}, \Delta_{2}$ and $\Delta_{3}$.

\section{Experimental Procedure}

\subsection{Elastoplastic Anisotropic}

The standard-steel specified as E24 in accordance with the NF A 35-573/4 (France Standard Structural steel) (United States Equivalent Grades: A283C and European Union Equivalent Grades: S235) is chosen as reference material. It is a structural grade steel with a minimum yield strength which widely used in the engineering and construction industries. With minimum yield strength, E24 structural steel is a common carbon structural steel that can be used in a very broad range of fabrication processes and its plate has excellent formability. It is often favored by the engineer trying to maximize strength or structure while minimizing its weight.

The procedure used to identify the material parameters of the anisotropic elastoplastic behavior coupled to ductile damage of the reference material E24 is described in a previous works [29]. The parameters concerning the anisotropy and the hardening of sheet are given starting from the local rational curves (stress/strain) of the tensile tests for three rolling directions (Figure 2), whereas the global predicted curved (tensile force/elongation) is used obtained to the best plastic stress flow evolutions model representing the behavior of the used material.

The tensile tests were carried out at a strain rate of $10^{-3} \mathrm{~s}^{-1}$ at room temperature of $25^{\circ} \mathrm{C}$. The tensile tests of the $0^{\circ}$ oriented specimens were taken as reference. Table 1 presents the anisotropy coefficients of the sheet material E24 determined experimentally using the Lankford coefficients $\left(r_{0}, r_{45}\right.$ and $\left.r_{90}\right)$ [29].

\subsection{Summary of Finite Element Modeling of the Tensile Tests}

A three-dimensional finite element analysis (FEA) has been performed using the finite

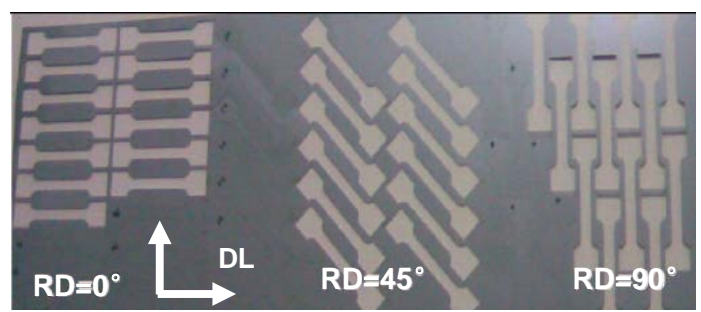

Figure 2. Oriented tensile test specimens of standard steel E24 (NF A03-151). 
element code ABAQUS/Standard to investigate the tensile test. The imposed boundary conditions on the $0^{\circ}$ oriented specimens (NF A03-151) include a fixed end on the side of the stationary grip and a uniform displacement on the side of the moving grip. The finite element type "C3D8R" used, are eight-node three-dimensional continuum elements with reduced linear integration; the mesh size is 2391 elements. For a given constitutive law, the numerical model returns the computed response as a tensile force/ elongation curve.

\subsection{Building of the Database for Analysis}

To build the database for analysis the three steps above are applied on two identification phases: hardening phase and damage phase.

The collected data for hardening phase is made up from a set of simulations based on full factorial design. The independents variables consist in a virtual hardening material parameters $\left(K, \varepsilon_{0}, n\right)$ of the uncoupled constitutive law (Swift model $D=0$; Equation (4)). Table 2 illustrates the values of the levels of the hardening material parameters used to generate the full factorial design $\mathrm{P}_{3}\left(3^{3}\right)$ (where $3^{3}=(\text { levels number })^{\text {factors number }}$ ). These levels were chosen within the variability limits of the hardening coefficients observed for steels.

Each combination of the full factorial design is used to implement the uncoupled constitutive law in ABAQUS/Standard to perform simulation of the tensile test. The dependent variables are the shape indexes of the computed tensile force/elongation curve of the simulation test. Eight shape indexes are retained for the identification of the hardening parameters; they are the coordinates of the points $\mathrm{A}, \mathrm{D}$ and $\mathrm{E}$ and the slopes of the tangent lines $\Delta_{1}$ and $\Delta_{3}$ (Figure 1). A relationship is built by multiple linear regression for each hardening material parameter in function of the selected shape indexes.

Making use of the shape indexes extracted from the experimental tensile curve, the relationships are used to get the results of the parameter identification of the uncoupled model of the reference material.

Table 1. Characteristic parameters of standard-steel E24.

\begin{tabular}{ccccccccccc}
\hline \multicolumn{3}{c}{ Mechanical properties } & \multicolumn{3}{c}{ Lankford coefficients } & \multicolumn{4}{c}{ Anisotropy parameters } \\
\hline Modulus of & Poisson's & Yield stress & $r_{0}$ & $r_{45}$ & $r_{90}$ & $F$ & $G$ & $H$ & $N$ \\
elasticity (GPa) & ratio & $(\mathrm{GPa})$ & 1.985 & 1.234 & 1.637 & 0.665 & 0.335 & 0.406 & 1.285 \\
210 & 0.33 & 195 & 1.95 & \\
\hline
\end{tabular}

Table 2. Levels used for the hardening coefficients.

\begin{tabular}{|c|c|c|c|c|}
\hline \multirow{2}{*}{ Influencing factors } & \multirow{2}{*}{ Label } & \multicolumn{3}{|c|}{ Levels } \\
\hline & & 1 & 2 & 3 \\
\hline Hardening modulus (MPa) & $K$ & 550 & 700 & 850 \\
\hline Initial strain (\%) & $\varepsilon_{0}$ & 0.575 & 1.05 & 1.525 \\
\hline Hardening coefficient & $n$ & 0.2 & 0.25 & 0.3 \\
\hline
\end{tabular}


The coefficients $\left(K, \varepsilon_{0}, n\right)$ identified above are treated as constants and used to address the damage phase of identification. The collected data is made up from a new full factorial design $\mathrm{P}_{3}\left(3^{3}\right)$ where the simulations are conducted using the coupled constitutive law $(D \neq 0$; Equation (3)). The independents variables consist in a virtual damage material parameters $\left(\gamma, \varepsilon_{s}, \varepsilon_{u}\right)$. Table 3 illustrates the values of the levels of the damage material parameters used to generate the full factorial design $\mathrm{P}_{3}\left(3^{3}\right)$; they are chosen in the range available for steels.

Eight other shape indexes are retained for the identification of the damage parameters; they are the coordinates of the points $\mathrm{A}, \mathrm{B}$ and $\mathrm{C}$ and the slopes of the tangent lines $\Delta_{1}$ and $\Delta_{2}$. A relationship is built by multiple linear regression for each damage material parameter in function of the new selected shape indexes.

Finally, the shape indexes extracted from the experimental tensile curve are introduced to the relationships to get the results of the parameter identification of the uncoupled model of the reference material.

Figure 3 exposes the identification procedure of the reference material parameters.

Table 3. Levels used for the damage coefficients.

\begin{tabular}{ccccc}
\hline Influencing factors & Label & \multicolumn{3}{c}{ Levels } \\
\cline { 3 - 5 } & & 1 & 2 & 3 \\
\hline Damage threshold (\%) & $\varepsilon_{s}$ & 0.5 & 0.625 & 0.75 \\
Total cumulated plastic strain (\%) & $\varepsilon_{u}$ & 50 & 60 & 70 \\
Damage index & $\gamma$ & 5 & 7.25 & 9.5 \\
\hline
\end{tabular}

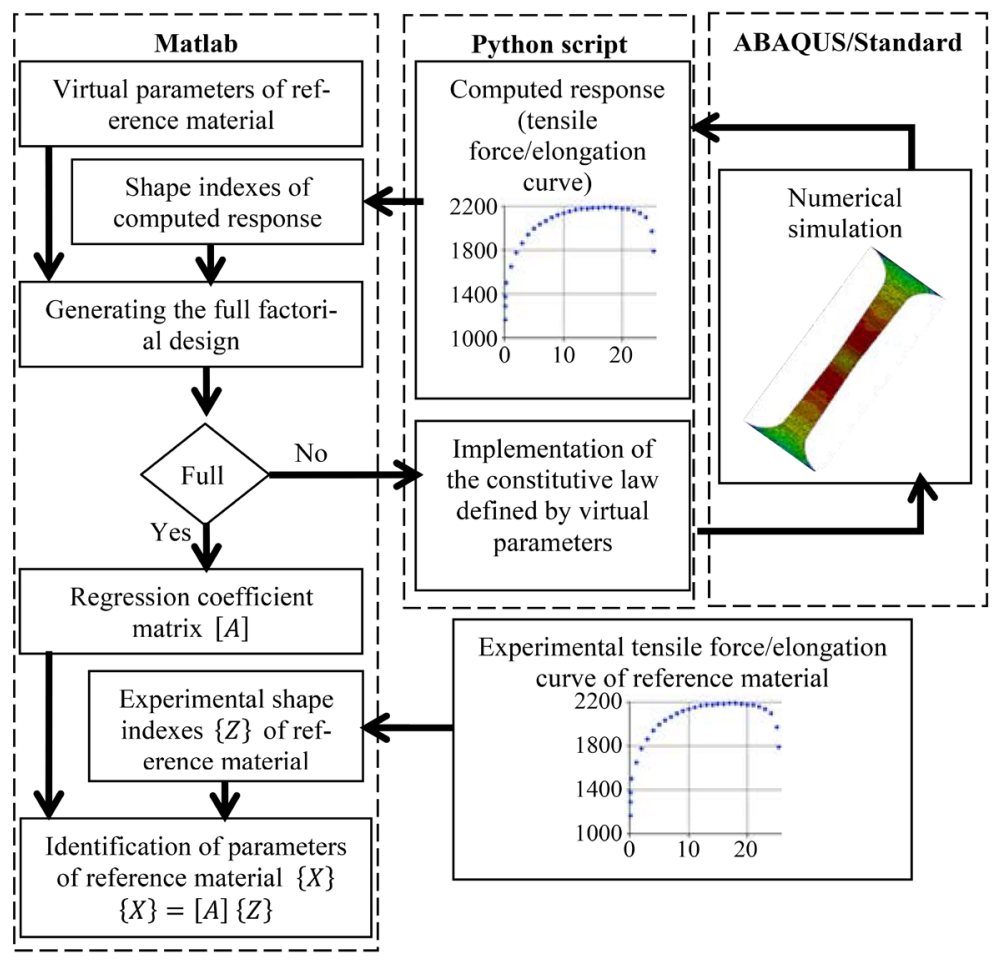

Figure 3. Identification procedure of the reference material parameters. 
The procedure involves running ABAQUS/Standard from a python script with input from an Excel file which holds the full factorial design. The Excel file can be easily parameterized and analyzed within the Matlab software.

Once results have been validated through both Equations (10) and (11), all materials verifying the equivalence relation (12) belong to the equivalence class $\{S\}$ (Equation (15)) constituted by the reference material.

\section{Identification Results of Reference Material}

\subsection{Identification of the Hardening Material Parameters}

Twenty seven simulations of tensile test according to the full factorial design $\mathrm{P}_{3}\left(3^{3}\right)$ are run. The different combinations of the virtual hardening parameters are defined in accordance with levels in Table 2. Table 4 shows for each combination introduced to implement the uncoupled constitutive law in ABAQUS, the shape indexes extracted from the computed tensile force/elongation curves.

Table 4. The full factorial design of the simulation results in hardening case.

\begin{tabular}{|c|c|c|c|c|c|c|c|c|c|c|c|}
\hline \multirow[b]{2}{*}{$P_{3}\left(3^{3}\right)$} & \multicolumn{3}{|c|}{$\begin{array}{l}\text { Virtual hardening } \\
\text { parameters }\end{array}$} & \multicolumn{8}{|c|}{$\begin{array}{c}\text { Shape indexes of simulation tensile force/elongation } \\
\text { curves (Hardening case) }\end{array}$} \\
\hline & $\begin{array}{c}K \\
(\mathrm{MPa})\end{array}$ & $\begin{array}{c}\varepsilon_{0} \\
(\%)\end{array}$ & $n$ & $\begin{array}{c}\delta_{E} \\
(\mathrm{~mm})\end{array}$ & $\begin{array}{c}F_{E} \\
(\mathrm{~N})\end{array}$ & $\begin{array}{c}\delta_{D} \\
(\mathrm{~mm})\end{array}$ & $\begin{array}{l}F_{D} \\
(\mathrm{~N})\end{array}$ & $\begin{array}{c}\delta_{A} \\
(\mathrm{~mm})\end{array}$ & $\begin{array}{c}F_{A} \\
(\mathrm{~N})\end{array}$ & $\begin{array}{c}p_{3} \\
(\mathrm{~N} / \mathrm{mm})\end{array}$ & $\begin{array}{c}p_{1} \\
(\mathrm{~N} / \mathrm{mm})\end{array}$ \\
\hline 1 & 1 & 1 & 1 & 0.25 & 1486 & 2.86 & 2475 & 15.37 & 2459 & 379 & -1.25 \\
\hline 2 & 2 & 1 & 1 & 0.25 & 1884 & 2.93 & 3152 & 15.47 & 3129 & 472 & -1.78 \\
\hline 3 & 3 & 1 & 1 & 0.25 & 2271 & 2.92 & 3827 & 15.44 & 3798 & 583 & -2.27 \\
\hline 4 & 1 & 2 & 1 & 0.25 & 1670 & 3.09 & 2490 & 15.34 & 2470 & 289 & -1.62 \\
\hline 5 & 2 & 2 & 1 & 0.25 & 2118 & 3.21 & 3181 & 15.32 & 3144 & 359 & -3.02 \\
\hline 6 & 3 & 2 & 1 & 0.25 & 2561 & 3.24 & 3863 & 15.35 & 3817 & 436 & -3.76 \\
\hline 7 & 1 & 3 & 1 & 0.25 & 1797 & 3.36 & 2512 & 14.76 & 2483 & 229 & -2.49 \\
\hline 8 & 2 & 3 & 1 & 0.25 & 2278 & 3.38 & 3197 & 14.65 & 3159 & 293 & -3.33 \\
\hline 9 & 3 & 3 & 1 & 0.25 & 2757 & 3.43 & 3882 & 14.86 & 3835 & 354 & -4.08 \\
\hline 10 & 1 & 1 & 2 & 0.25 & 1163 & 3.06 & 2201 & 17.32 & 2280 & 370 & 5.55 \\
\hline 11 & 2 & 1 & 2 & 0.25 & 1468 & 3.00 & 2786 & 17.41 & 2900 & 479 & 7.97 \\
\hline 12 & 3 & 1 & 2 & 0.25 & 1779 & 3.05 & 3355 & 17.38 & 3522 & 562 & 11.62 \\
\hline 13 & 1 & 2 & 2 & 0.25 & 1342 & 3.31 & 2218 & 17.28 & 2292 & 286 & 5.31 \\
\hline 14 & 2 & 2 & 2 & 0.25 & 1698 & 3.34 & 2839 & 17.22 & 2916 & 369 & 5.57 \\
\hline 15 & 3 & 2 & 2 & 0.25 & 2056 & 3.33 & 3413 & 17.31 & 3540 & 440 & 9.12 \\
\hline 16 & 1 & 3 & 2 & 0.25 & 1465 & 3.45 & 2240 & 17.28 & 2304 & 242 & 4.64 \\
\hline 17 & 2 & 3 & 2 & 0.25 & 1860 & 3.56 & 2855 & 17.16 & 2931 & 301 & 5.54 \\
\hline 18 & 3 & 3 & 2 & 0.25 & 2250 & 3.57 & 3461 & 17.18 & 3557 & 365 & 7.09 \\
\hline 19 & 1 & 1 & 3 & 0.25 & 909 & 3.16 & 1948 & 17.92 & 2109 & 357 & 10.92 \\
\hline 20 & 2 & 1 & 3 & 0.25 & 1155 & 3.19 & 2451 & 17.85 & 2684 & 440 & 15.89 \\
\hline 21 & 3 & 1 & 3 & 0.25 & 1390 & 3.21 & 3006 & 17.85 & 3256 & 546 & 17.08 \\
\hline 22 & 1 & 2 & 3 & 0.25 & 1079 & 3.49 & 1977 & 17.84 & 2126 & 278 & 10.33 \\
\hline 23 & 2 & 2 & 3 & 0.25 & 1367 & 3.48 & 2507 & 17.85 & 2704 & 352 & 13.74 \\
\hline 24 & 3 & 2 & 3 & 0.25 & 1653 & 3.48 & 3030 & 17.85 & 3282 & 427 & 17.51 \\
\hline 25 & 1 & 3 & 3 & 0.25 & 1197 & 3.62 & 1999 & 17.91 & 2139 & 238 & 9.81 \\
\hline 26 & 2 & 3 & 3 & 0.25 & 1520 & 3.70 & 2546 & 17.84 & 2723 & 298 & 12.49 \\
\hline 27 & 3 & 3 & 3 & 0.25 & 1839 & 3.69 & 3079 & 17.84 & 3304 & 360 & 15.89 \\
\hline
\end{tabular}


As a predictive analysis, the Matlab stepwise linear regression is used to select the most important shape indexes that contribute to the hardening parameter variations. This stepwise method keeps the number of potential variables to a minimum. The coefficients $\left(a_{1 i}\right)$ of the regression Equation (16) are expressed in Table 5.

$$
x_{h}=a_{10}+a_{11} \delta_{E}+a_{12} F_{E}+a_{13} \delta_{D}+a_{14} F_{D}+a_{15} \delta_{A}+a_{16} F_{A}+a_{17} p_{3}+a_{18} p_{1}
$$

where $x_{h}$ expresses the hardening parameter $\left(K, \varepsilon_{0}, n\right)$; and $\left(\delta_{E}, F_{E}, \delta_{D}, F_{D}, \delta_{A}, F_{A}, p_{3}, p_{1}\right)$ are the hardening shape indexes of the tensile force/elongation graph.

The results show that two shape indexes $\left(\delta_{E}, F_{D}\right)$ do not have any effect on any one of the hardening parameters. It is stated that $99.9 \%, 94.4 \%$ and $95.3 \%$ of the variability of $K, \varepsilon_{0}$ and $n$, respectively are explained. These high values of $\mathrm{R}^{2}$ indicate that the models of hardening material parameters have a good fit. $K, \varepsilon_{0}$ and $n$ can therefore be identified by introducing the shape indexes obtained from the experimental tensile force/elongation graph (Table 6) in the reduced Equation (17):

$$
x_{h}=a_{10}+a_{12} F_{E}+a_{13} \delta_{D}+a_{15} \delta_{A}+a_{16} F_{A}+a_{17} p_{3}+a_{18} p_{1}
$$

The results of the parameter identification are presented in Table 7 . In Figure 4, a comparison between the tensile force/elongation graph obtained by simulation with the uncoupled Swift model and the experimental graph for standard-steel E24 tested at

Table 5. Data analysis results from the $\mathrm{P}_{3}\left(3^{3}\right)$ for the hardening case (standard-steel E24).

\begin{tabular}{cccc}
\hline Coefficient & $K$ & $\varepsilon_{0}$ & $n$ \\
\hline $\mathrm{a}_{10}$ & -18.247 & -0.044836 & 0.087771 \\
$\mathrm{a}_{11}$ & 0 & 0 & 0 \\
$\mathrm{a}_{12}$ & -0.25195 & 0 & 0 \\
$\mathrm{a}_{13}$ & 27.393 & 0.017289 & 0 \\
$\mathrm{a}_{14}$ & 0 & 0 & 0 \\
$\mathrm{a}_{15}$ & -3.4644 & 0 & 0.0098491 \\
$\mathrm{a}_{16}$ & 0.43379 & 0 & 0 \\
$\mathrm{a}_{17}$ & -0.40557 & 0 & $-7.47 \mathrm{E}-05$ \\
$\mathrm{a}_{18}$ & 0 & -0.00028498 & 0.0041557 \\
$\mathrm{R}^{2}$ & $99.9 \%$ & $94.4 \%$ & $95.3 \%$ \\
$\mathrm{R}^{2} \mathrm{adj}$ & $99.9 \%$ & $93.9 \%$ & $94.7 \%$ \\
$\mathrm{RMSE}$ & 2.98 & 0.000973 & 0.00962
\end{tabular}

Table 6. Shape indexes of the experimental tensile force/elongation graph of standard-steel E24 (at $25^{\circ} \mathrm{C}$ and $10^{-3} \mathrm{~s}^{-1}$ ).

\begin{tabular}{cccccccc}
\hline \multicolumn{2}{c}{$\mathrm{E}$} & \multicolumn{2}{c}{$\mathrm{D}$} & \multicolumn{2}{c}{$\mathrm{A}$} & $\Delta_{3}$ & $\Delta_{1}$ \\
\hline$\delta_{E}(\mathrm{~mm})$ & $F_{E}(\mathrm{~N})$ & $\delta_{D}(\mathrm{~mm})$ & $F_{D}(\mathrm{~N})$ & $\delta_{A}(\mathrm{~mm})$ & $F_{A}(\mathrm{~N})$ & $p_{3}(\mathrm{~N} / \mathrm{mm})$ & $p_{1}(\mathrm{~N} / \mathrm{mm})$ \\
\hline 0.2489 & 1525.8 & 3.6949 & 2172.1 & 16.3284 & 2193.8 & 187.5335 & 1.7213 \\
\hline
\end{tabular}


Table 7. Parameter identification results of the hardening parameters of standard-steel E24 at $\left(25^{\circ} \mathrm{C}\right.$ and $\left.10^{-3} \mathrm{~s}^{-1}\right)$.

\begin{tabular}{ccccc}
\hline \multirow{2}{*}{ Full factorial design } & Parameters & \multicolumn{2}{c}{ Average error } \\
\cline { 2 - 5 } & $K(\mathrm{MPa})$ & $\varepsilon_{0}(\%)$ & $n$ & $\xi_{F}(\%)$ \\
\hline $\mathrm{P}_{3}\left(3^{3}\right)$ & 517.56 & 1.86 & 0.242 & 0.20 \\
\hline
\end{tabular}

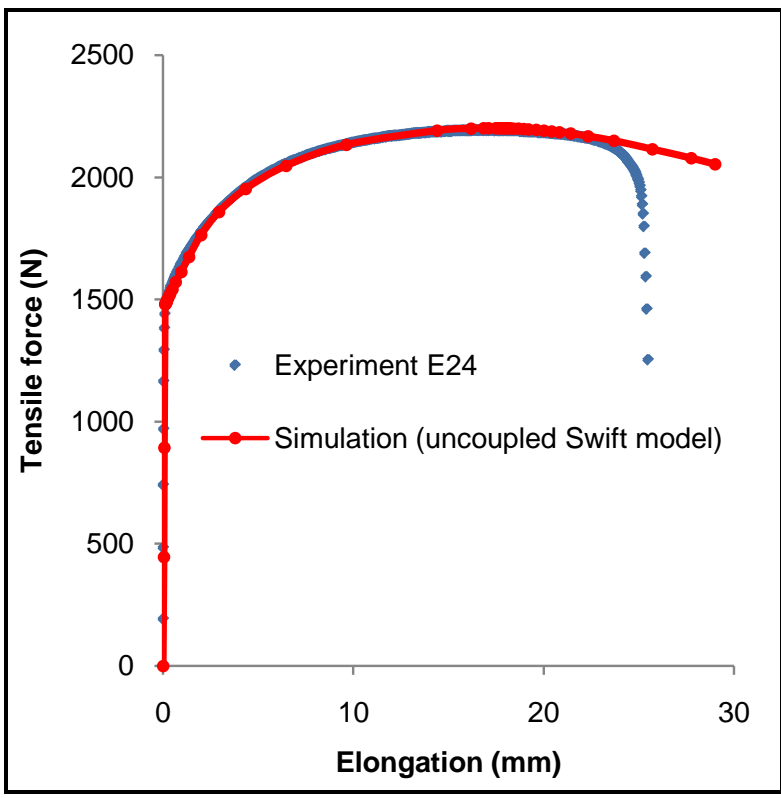

Figure 4. Tensile curves: experimental vs. simulated uncoupled Swift Model of standard steel E24 $\left(25^{\circ} \mathrm{C}\right.$ and $10^{-3}$ $\left.\mathrm{s}^{-1}\right)$.

$\left(25^{\circ} \mathrm{C}\right.$ and $\left.10^{-3} \mathrm{~s}^{-1}\right)$ is presented. The average relative error $\xi_{F}$ of $0.2 \%$ of the hardening portion of the graph (between $0.05 \mathrm{~mm}$ and $17 \mathrm{~mm}$ ) was observed indicating good agreement between the two graphs.

\subsection{Identification of the Damage Material Parameters}

The hardening material parameters $\left(K=517.56, \varepsilon_{0}=1.86, n=0.242\right)$ identified above (Table 7) are used to perform the damage phase of identification. Twenty seven simulations of tensile test according to a new full factorial design $\mathrm{P}_{3}\left(3^{3}\right)$ are run. The different combinations of the virtual damage parameters $\left(\gamma, \varepsilon_{s}, \varepsilon_{u}\right)$ are defined in accordance with levels in Table 3. Table 8 shows all combinations introduced to implement the coupled constitutive law ( $D \neq 0$; Equation (3)) in ABAQUS. It also shows the shape indexes extracted from the damage side of the computed tensile force/elongation curves.

The coefficients $\left(a_{2 i}\right)$ of the multiple regression Equation (18) are expressed in Table 8.

$$
x_{d}=a_{20}+a_{21} \delta_{C}+a_{22} F_{C}+a_{23} \delta_{B}+a_{24} F_{B}+a_{25} \delta_{A}+a_{26} F_{A}+a_{27} p_{1}+a_{28} p_{2}
$$

where $x_{d}$ is a damage parameter $\left(\varepsilon_{s}, \varepsilon_{u}\right.$ and $\left.\gamma\right) ; \delta_{A}, F_{A}, \delta_{B}, F_{B}, \delta_{O} F_{O} p_{1}$ and $p_{2}$ are the damage shape indexes of the tensile force/elongation graph. 
Table 8. The full factorial design of the simulation results in damage case.

\begin{tabular}{|c|c|c|c|c|c|c|c|c|c|c|c|}
\hline \multirow[b]{2}{*}{$P_{3}\left(3^{3}\right)$} & \multicolumn{3}{|c|}{$\begin{array}{l}\text { Virtual damage } \\
\text { parameters }\end{array}$} & \multicolumn{8}{|c|}{$\begin{array}{l}\text { Shape indexes of simulation tensile force/elongation curves } \\
\text { (Damage case) }\end{array}$} \\
\hline & $\begin{array}{c}\varepsilon_{s} \\
(\%)\end{array}$ & $\begin{array}{c}\varepsilon_{u} \\
(\%)\end{array}$ & $\gamma$ & $\begin{array}{c}\delta_{C} \\
(\mathrm{~mm})\end{array}$ & $\begin{array}{l}F_{C} \\
(\mathrm{~N}) \\
\end{array}$ & $\begin{array}{c}\delta_{B} \\
(\mathrm{~mm})\end{array}$ & $\begin{array}{c}F_{B} \\
(\mathrm{~N})\end{array}$ & $\begin{array}{c}\delta_{A} \\
(\mathrm{~mm})\end{array}$ & $\begin{array}{c}F_{A} \\
(\mathrm{~N})\end{array}$ & $\begin{array}{c}p_{1}\left(\Delta_{1}\right) \\
(\mathrm{N} / \mathrm{mm})\end{array}$ & $\begin{array}{c}p_{2}\left(\Delta_{2}\right) \\
(\mathrm{N} / \mathrm{mm})\end{array}$ \\
\hline 1 & 1 & 1 & 1 & 17.71 & 1950 & 17.51 & 2180 & 14.19 & 2179 & 0.37 & -1136 \\
\hline 2 & 2 & 1 & 1 & 17.66 & 1512 & 17.59 & 2176 & 14.19 & 2178 & -0.64 & -10634 \\
\hline 3 & 3 & 1 & 1 & 17.55 & 1998 & 17.28 & 2177 & 14.19 & 2178 & -0.17 & -669 \\
\hline 4 & 1 & 2 & 1 & 20.79 & 1633 & 20.70 & 2187 & 15.51 & 2191 & -0.71 & -6095 \\
\hline 5 & 2 & 2 & 1 & 20.74 & 1873 & 20.49 & 2191 & 15.46 & 2191 & 0.19 & -1318 \\
\hline 6 & 3 & 2 & 1 & 20.63 & 1891 & 20.39 & 2191 & 15.46 & 2190 & 0.18 & -1300 \\
\hline 7 & 1 & 3 & 1 & 24.04 & 1857 & 23.45 & 2195 & 16.34 & 2197 & -0.27 & -582 \\
\hline 8 & 2 & 3 & 1 & 24.04 & 1821 & 23.57 & 2203 & 15.90 & 2196 & 0.91 & -818 \\
\hline 9 & 3 & 3 & 1 & 23.87 & 1868 & 23.23 & 2203 & 15.90 & 2196 & 0.94 & -528 \\
\hline 10 & 1 & 1 & 2 & 20.41 & 2000 & 20.16 & 2195 & 16.34 & 2198 & -0.69 & -799 \\
\hline 11 & 2 & 1 & 2 & 20.35 & 2009 & 20.11 & 2200 & 16.06 & 2198 & 0.44 & -793 \\
\hline 12 & 3 & 1 & 2 & 20.30 & 2009 & 20.06 & 2198 & 16.06 & 2198 & 0.22 & -813 \\
\hline 13 & 1 & 2 & 2 & 23.65 & 1989 & 23.48 & 2195 & 17.44 & 2201 & -1.06 & -1228 \\
\hline 14 & 2 & 2 & 2 & 23.65 & 1964 & 23.46 & 2195 & 17.44 & 2201 & -1.10 & -1205 \\
\hline 15 & 3 & 2 & 2 & 23.65 & 1932 & 23.46 & 2194 & 17.44 & 2201 & -1.16 & -1387 \\
\hline 16 & 1 & 3 & 2 & 27.34 & 1782 & 26.74 & 2201 & 17.44 & 2203 & -0.23 & -705 \\
\hline 17 & 2 & 3 & 2 & 27.28 & 1754 & 26.79 & 2201 & 17.44 & 2203 & -0.19 & -905 \\
\hline 18 & 3 & 3 & 2 & 27.23 & 1774 & 26.70 & 2200 & 17.44 & 2203 & -0.30 & -809 \\
\hline 19 & 1 & 1 & 3 & 22.00 & 1999 & 21.78 & 2198 & 17.44 & 2202 & -0.87 & -910 \\
\hline 20 & 2 & 1 & 3 & 21.89 & 2012 & 21.67 & 2198 & 17.44 & 2202 & -0.90 & -846 \\
\hline 21 & 3 & 1 & 3 & 21.84 & 1997 & 21.62 & 2199 & 17.44 & 2202 & -0.81 & -953 \\
\hline 22 & 1 & 2 & 3 & 25.52 & 1872 & 25.21 & 2204 & 17.44 & 2203 & 0.05 & -1054 \\
\hline 23 & 2 & 2 & 3 & 25.47 & 1828 & 25.22 & 2204 & 17.44 & 2203 & 0.04 & -1515 \\
\hline 24 & 3 & 2 & 3 & 25.41 & 1867 & 25.14 & 2205 & 17.44 & 2203 & 0.20 & -1251 \\
\hline 25 & 1 & 3 & 3 & 29.15 & 1756 & 28.58 & 2204 & 17.44 & 2204 & 0.01 & -783 \\
\hline 26 & 2 & 3 & 3 & 29.10 & 1727 & 28.68 & 2205 & 17.44 & 2204 & 0.12 & -1145 \\
\hline 27 & 3 & 3 & 3 & 28.99 & 1756 & 28.48 & 2204 & 17.44 & 2204 & 0.07 & -885 \\
\hline
\end{tabular}

The results of the analysis presented in Table 9 show that the damage threshold parameter $\varepsilon_{\mathrm{s}}$ does not depend of the shape indexes. In fact, it may be considered as a parameter intrinsic to the material and related to the initial damage in the sheet metal. However, none of the five shape indexes $\left(F_{B}, \delta_{A}, F_{A}, p_{1}, p_{2}\right)$ has no effect on damage parameters. The coefficients of determination show that the linear regression relations obtained explain $84.6 \%$ of the variability in the cumulated total plastic deformation $\varepsilon_{u l}(\%)$ and $67 \%$ of the variability in the damage index $\gamma$. 
The identification of the damage material parameters $\varepsilon_{u}$ and $\gamma$ are now achieved by introducing the damage shape indexes, of the experimental tensile force/elongation curve presented in Table 10, in the reduced Equation (19).

$$
x_{d}=a_{20}+a_{21} \delta_{C}+a_{22} F_{C}+a_{23} \delta_{B}
$$

The identification results of the damage material parameters are presented in Table 11. The tensile force/elongation graph computed using the coupled Swift model is compared to its experimental counterpart for standard-steel E24 in Figure 5. The average relative error $\xi_{U}$ between the elongations of the two graphs is on the order of $0.34 \%$ confirming the accuracy of the predicted response of the identified model.

To recap, the coupled Swift model of standard-steel E24 depicted by the anisotropic elastoplastic behavior coupled to ductile damage of the reference material E24 is described by the constitutive model (Equation (20)). The material parameters are identified above (Table 7 and Table 11).

Table 9. Data analysis results from the $\mathrm{P}_{3}\left(3^{3}\right)$ for the damage case (standard-steel E24).

\begin{tabular}{cccc}
\hline Coefficient & $\varepsilon_{s}$ & $\varepsilon_{u}$ & $\gamma$ \\
\hline $\mathrm{a}_{20}$ & 0.00625 & 0.62376 & -15.294 \\
$\mathrm{a}_{21}$ & 0 & 0.24571 & -6.8441 \\
$\mathrm{a}_{22}$ & 0 & -0.00017488 & 0.0055914 \\
$\mathrm{a}_{23}$ & 0 & -0.23597 & 7.4649 \\
$\mathrm{a}_{24}$ & 0 & 0 & 0 \\
$\mathrm{a}_{25}$ & 0 & 0 & 0 \\
$\mathrm{a}_{26}$ & 0 & 0 & 0 \\
$\mathrm{a}_{27}$ & 0 & 0 & 0 \\
$\mathrm{a}_{28}$ & 0 & 0 & 0 \\
$\mathrm{R}^{2}$ & & $84.6 \%$ & $67 \%$ \\
$\mathrm{R}^{2} \mathrm{adj}$ & & $82.6 \%$ & $62.7 \%$ \\
$\mathrm{RMSE}$ & 0.104 & 0.0347 & 1.14 \\
\hline
\end{tabular}

Table 10. Experimental values of the shape indexes to characterize damage of standard-steel E24 at $\left(10^{-3} \mathrm{~s}^{-1}\right.$ and $\left.25^{\circ} \mathrm{C}\right)$.

\begin{tabular}{cccccccc}
\hline \multicolumn{2}{c}{$\mathrm{C}$} & \multicolumn{2}{c}{$\mathrm{B}$} & \multicolumn{2}{c}{$\mathrm{A}$} & $\Delta_{1}$ & $\Delta_{2}$ \\
\hline$\delta_{C}(\mathrm{~mm})$ & $F_{C}(\mathrm{~N})$ & $\delta_{B}(\mathrm{~mm})$ & $F_{B}(\mathrm{~N})$ & $\delta_{A}(\mathrm{~mm})$ & $F_{A}(\mathrm{~N})$ & $p_{1}(\mathrm{~N} / \mathrm{mm})$ & $p_{2}(\mathrm{~N} / \mathrm{mm})$ \\
\hline 25.3856 & $1.59 \mathrm{E}+03$ & 25.1719 & $2.17 \mathrm{E}+03$ & 18.0415 & $2.19 \mathrm{E}+03$ & -3.2085 & $-2.70 \mathrm{E}+03$ \\
\hline
\end{tabular}

Table 11. Damage parameter identification results for standard-steel E24 at $\left(25^{\circ} \mathrm{C}\right.$ and $\left.10^{-3} \mathrm{~s}^{-1}\right)$.

\begin{tabular}{ccccc}
\hline \multirow{2}{*}{ Full factorial design } & \multicolumn{3}{c}{ Parameters } & \multicolumn{2}{c}{ Average error } \\
\cline { 2 - 5 } & $\varepsilon_{s}(\%)$ & $\varepsilon_{u}(\%)$ & $\gamma$ & $\xi_{U}(\%)$ \\
\hline $\mathrm{P}_{3}\left(3^{3}\right)$ & 0.625 & 64.29 & 7.78 & 0.34 \\
\hline
\end{tabular}




$$
\sigma_{e q}=517.56\left(1-\left(\frac{\varepsilon_{e q}+0.625}{64.29}\right)^{7.78}\right)\left(1.86+\varepsilon_{e q}\right)^{0.242}
$$

In Figure 6, it presented the simulation result of the tensile force/elongation of the standard-steel E24. It shows the cumulated plastic equivalent strain fields and the Mises stress obtained from the numerical simulation. For elongations below $17 \mathrm{~mm}$ the cumulated plastic deformation as well as damage remained homogenous over the active region of the specimen. Beyond this limit the deformation becomes non-uniform and starts to localize in the middle section of the specimen when elongation reaches $21 \mathrm{~mm}$. Local necking is observed in the form of a shear band signaling the imminent initiation of a macroscopic crack. The agreement between the experimental observations and the identified model confirm the reliability of the proposed parameter identification procedure.

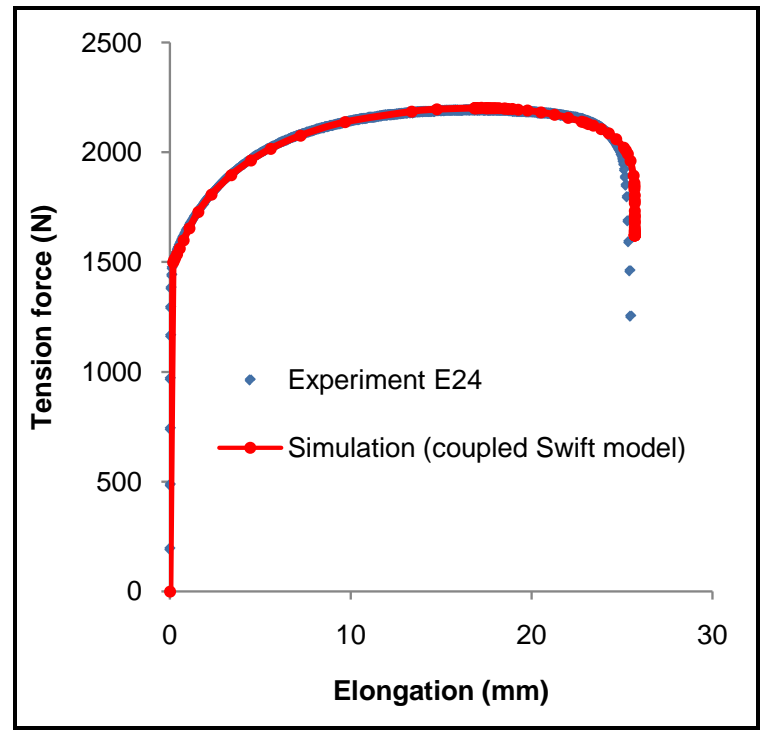

Figure 5. Tensile curves: experimental vs. simulated coupled Swift Model of standard-steel E24 $\left(25^{\circ} \mathrm{C}\right.$ and $\left.10^{-3} \mathrm{~s}^{-1}\right)$.

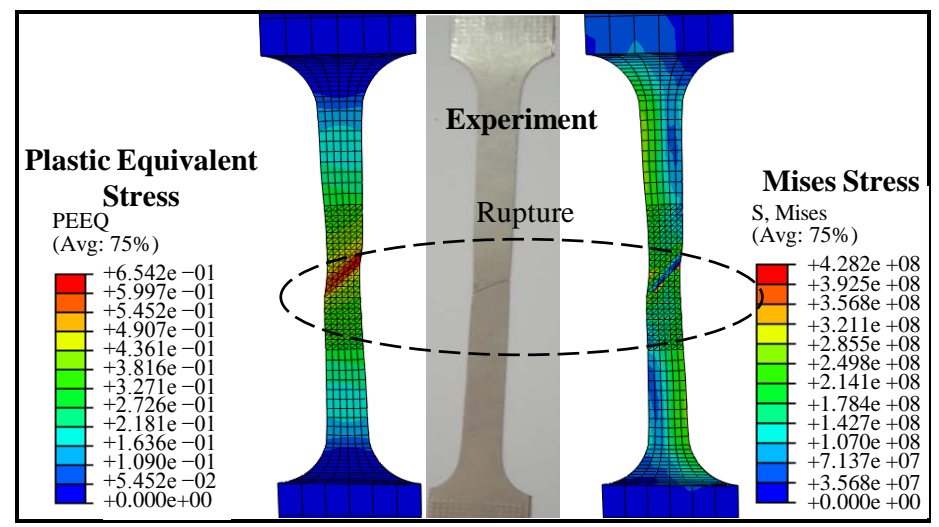

Figure 6. Plastic equivalent strain and Mises stress fields for the coupled Swift model of standard-steel E24. 


\subsection{Determination of the Equivalence Class}

The material parameters of the reference material are now identified this means that the equivalence class $\{S\}$ is now defined. For any other material whose the couple of parameters $\left(\{Y\},\left\{Z_{y}\right\}\right)$ is in accordance with Equation (14) belongs to the equivalence class $\{S\}$. This means that the material has a behavior partially similar to the reference material and is submitted to the same constitutive model. The material parameters $\{Y\}$ can be identified immediately by the Equation (21) which substitutes the Equation (8).

$$
\{Y\}=\left\{\begin{array}{c}
K \\
\varepsilon_{0} \\
n \\
\varepsilon_{s} \\
\varepsilon_{u} \\
\gamma
\end{array}\right\}=[A]\left\{\begin{array}{c}
1 \\
F_{E} \\
\delta_{D} \\
\delta_{A} \\
F_{A} \\
p_{3} \\
p_{1} \\
\delta_{C} \\
F_{C} \\
\delta_{B}
\end{array}\right\}
$$

Based on Equation (17) and Equation (19) the matrix $[A]$, where all values are extracted from Table 5 and Table 9 , is defined as:

$$
[A]=\left[\begin{array}{cccccccccc}
-18.25 & -0.252 & 27.393 & -3.464 & 0.4338 & -0.4056 & 0 & 0 & 0 & 0 \\
-0.045 & 0 & 0.0173 & 0 & 0 & 0 & -2.8 \times 10^{-4} & 0 & 0 & 0 \\
0.0878 & 0 & 0 & 0.0098 & 0 & -7.5 \times 10^{-5} & 0.0042 & 0 & 0 & 0 \\
0.0063 & 0 & 0 & 0 & 0 & 0 & 0 & 0 & 0 & 0 \\
0.6238 & 0 & 0 & 0 & 0 & 0 & 0 & 0.2457 & -1.7 \times 10^{-4} & -0.236 \\
-15.29 & 0 & 0 & 0 & 0 & 0 & 0 & -6.844 & 5.59 \times 10^{-3} & 7.4649
\end{array}\right]
$$

\section{Validation and Discussion}

The validation of this technique has been extended is extended to the identification of the coefficients of the coupled Swift model of:

1) The behavior of standard-steel E24 under other conditions of temperature and strain rate

2) The behavior in tension of a material with characteristics different from standard-steel E24 such as 1050A aluminum.

\subsection{Characterization of Standard-Steel E24 at $1.66 \times 10^{-1} \mathrm{~S}^{-1}$ Strain Rate}

The first implementation of this method is concerned with a tensile test of standardsteel E24 at a temperature of $25^{\circ} \mathrm{C}$ and a strain rate of $1.66 \times 10^{-3} \mathrm{~s}^{-1}$. Figure 7 shows the initiation of hardening; both graphs have similar features.

The experimental shape indexes from the tensile force/elongation graph are presented in Table 12. They are introduced in Equation (20) to calculate immediately the material parameters according to the coupled Swift model (Table 13). 


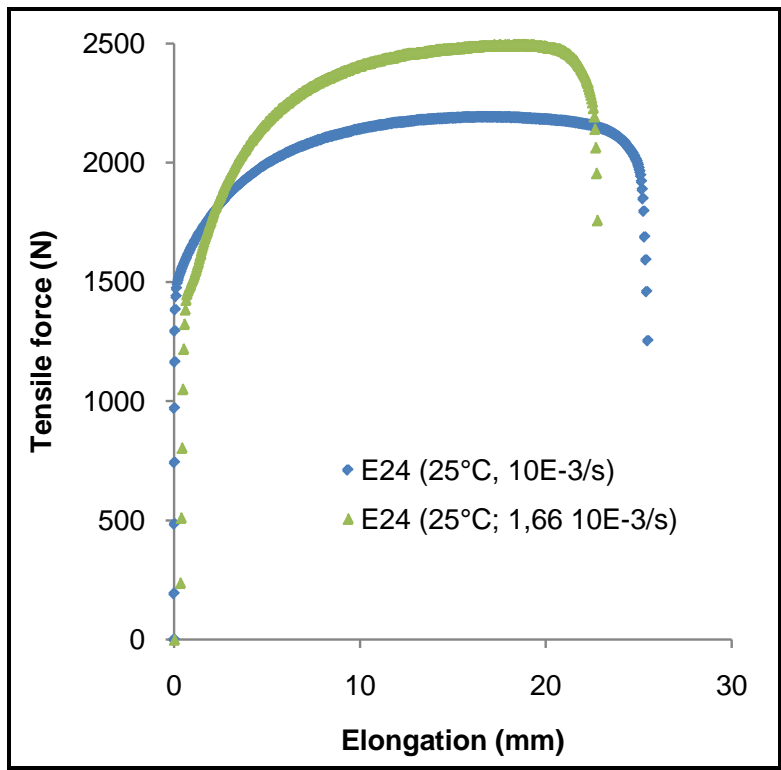

Figure 7. Comparison of the tensile curves of standard-steel E24 at different strain rates.

Table 12. Experimental values of the shape indexes of standard-steel E24 at $\left(1.66 \times 10^{-3} \mathrm{~s}^{-1}\right.$ and $\left.25^{\circ} \mathrm{C}\right)$.

\begin{tabular}{|c|c|c|c|c|c|c|c|}
\hline \multicolumn{8}{|c|}{ Hardening } \\
\hline \multicolumn{2}{|c|}{$\mathrm{E}$} & \multicolumn{2}{|c|}{$\mathrm{D}$} & \multicolumn{2}{|c|}{ A } & \multirow{2}{*}{$\frac{\Delta_{3}}{p_{3}(\mathrm{~N} / \mathrm{mm})}$} & \multirow{2}{*}{$\frac{\Delta_{1}}{p_{1}(\mathrm{~N} / \mathrm{mm})}$} \\
\hline$\delta_{E}(\mathrm{~mm})$ & $F_{E}(\mathrm{~N})$ & $\delta_{D}(\mathrm{~mm})$ & $F_{D}(\mathrm{~N})$ & $\delta_{A}(\mathrm{~mm})$ & $F_{A}(\mathrm{~N})$ & & \\
\hline 1.33 & 1598.60 & 4.32 & 2480.02 & 19.33 & 2496.56 & 295.06 & 1.10 \\
\hline \multicolumn{8}{|c|}{ Damage } \\
\hline \multicolumn{2}{|c|}{$\mathrm{C}$} & \multicolumn{2}{|c|}{ B } & \multicolumn{2}{|c|}{ A } & $\Delta_{1}$ & $\Delta_{2}$ \\
\hline$\delta_{C}(\mathrm{~mm})$ & $F_{C}(\mathrm{~N})$ & $\delta_{B}(\mathrm{~mm})$ & $F_{B}(\mathrm{~N})$ & $\delta_{A}(\mathrm{~mm})$ & $F_{A}(\mathrm{~N})$ & $p_{1}(\mathrm{~N} / \mathrm{mm})$ & $p_{2}(\mathrm{~N} / \mathrm{mm})$ \\
\hline 22.71 & 1957.0 & 22.5238 & 2503.70 & 19.33 & 2496.60 & 1.3427 & -2981.70 \\
\hline
\end{tabular}

Table 13. Identification of parameters for standard-steel E24 at $\left(1.66 \times 10^{-3} \mathrm{~s}^{-1} 25^{\circ} \mathrm{C}\right)$.

\begin{tabular}{|c|c|c|c|c|c|c|c|}
\hline \multicolumn{4}{|c|}{ Hardening } & \multicolumn{4}{|c|}{ Damage } \\
\hline \multicolumn{3}{|c|}{ Parameters } & \multirow{2}{*}{$\begin{array}{c}\text { Average error } \\
\xi_{F}(\%)\end{array}$} & \multicolumn{3}{|c|}{ Parameters } & \multirow{2}{*}{$\begin{array}{c}\text { Average error } \\
\xi_{U}(\%)\end{array}$} \\
\hline$K(\mathrm{MPa})$ & $\varepsilon_{0}(\%)$ & $n$ & & $\mathcal{E}_{s}(\%)$ & $\varepsilon_{u}(\%)$ & $\gamma$ & \\
\hline 593.63 & 2.951 & 0.261 & 0.33 & 0.625 & 54.5 & 8.375 & 0.34 \\
\hline
\end{tabular}

Figure 8 presents a comparison between the computed response using the coupled Swift model and the experimental response; the average relative error $\xi_{F}$ between the two responses is about $0.33 \%$ for elongations between $5.2 \mathrm{~mm}$ and $17.0 \mathrm{~mm}$. The average relative error $\xi_{U}$ for elongations between $17.0 \mathrm{~mm}$ and $23.0 \mathrm{~mm}$ is about $0.34 \%$. For elongations below $5.2 \mathrm{~mm}$ a difference exists which seems to be affected by the experimental shape indexes due to uncertainty in the coordinates of point $\mathrm{A}$ as well as the slope $p_{1}$ of the tangent line $\Delta_{1}$. 


\subsection{Characterization of Standard-Steel E24 at High Temperature}

The second application of the method is concerned with a tensile test of standard-steel E24 at $200^{\circ} \mathrm{C}$ and a strain rate of $1.66 \times 10^{-3} \mathrm{~s}^{-1}$. Figure 9 shows an acceptable level of agreement with the tensile graph of the reference test (standard-steel E24 at $25^{\circ} \mathrm{C}$ and $10^{-3} \mathrm{~s}^{-1}$ ); this makes it possible to identify the hardening and damage parameters directly for the tensile test of standard-steel E24 at $200^{\circ} \mathrm{C}$. The experimental shape indexes are presented in Table 14.

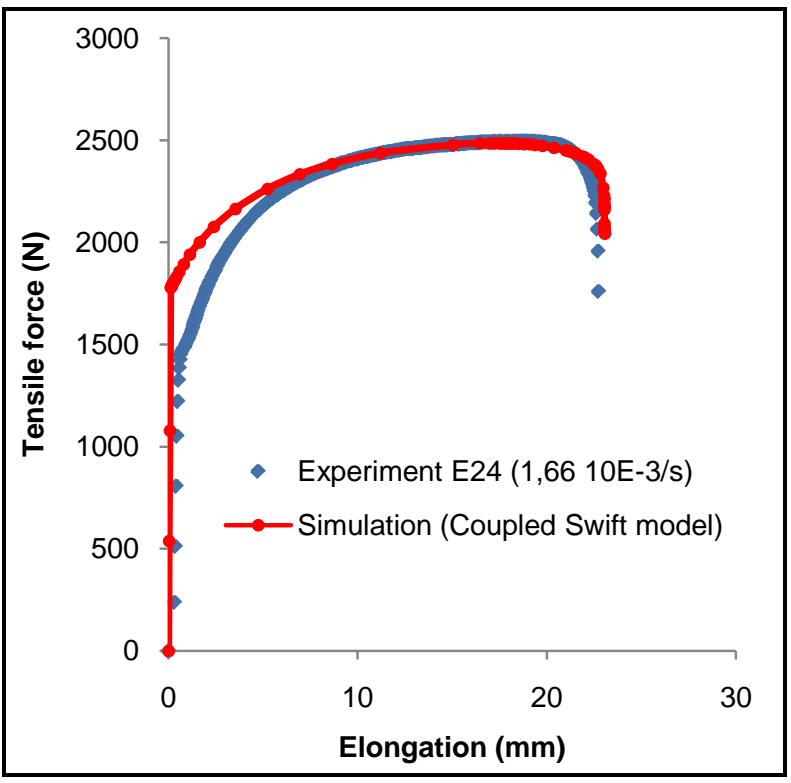

Figure 8. Tensile graphs of standard-steel E24: experimental $\left(1.66 \times 10^{-3} / \mathrm{s}\right)$ vs. simulated (coupled Swift model).

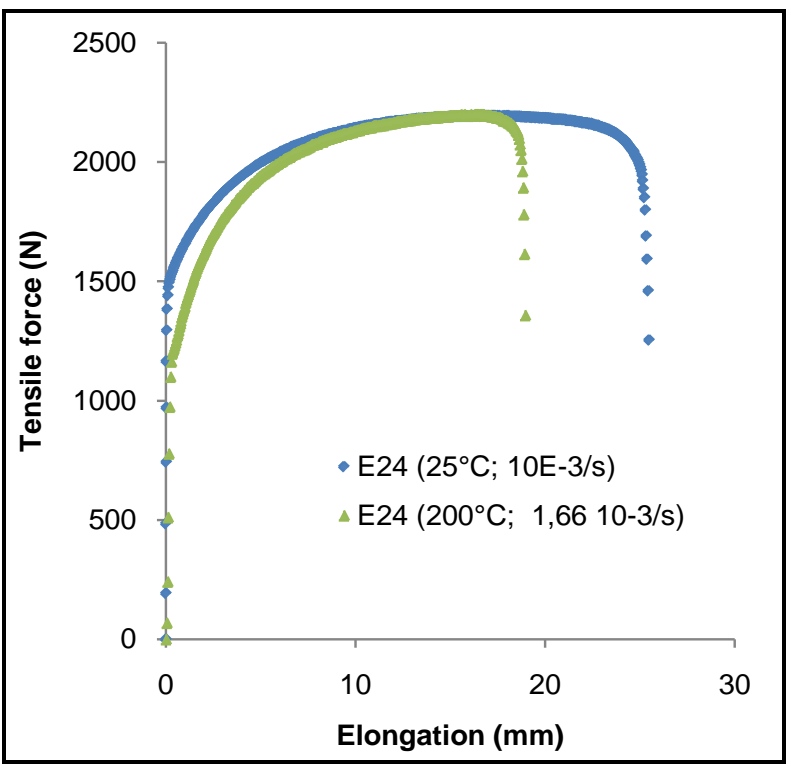

Figure 9. Experimental tensile graphs of standard-steel E24 under different conditions. 
The results of the identification of hardening and damage parameters by multiple regression at a temperature of $200^{\circ} \mathrm{C}$ are presented in Table 15. Figure 10 shows that below an elongation of $4.4 \mathrm{~mm}$ the experimental and simulated results display a difference. The average relative difference $\xi_{F}$ between the two responses is $0.22 \%$ for elongations below $14.6 \mathrm{~mm}$ whereas for elongations in the range $14.4 \mathrm{~mm}$ to $19.1 \mathrm{~mm}$ the average relative error $\xi_{U}$ is about $0.10 \%$.

Table 14. Experimental shape indexes of the standard-steel E24 at $\left(200^{\circ} \mathrm{C}\right.$ and $\left.1.66 \times 10^{-3} \mathrm{~s}^{-1}\right)$.

\begin{tabular}{|c|c|c|c|c|c|c|c|}
\hline \multicolumn{8}{|c|}{ Hardening } \\
\hline \multicolumn{2}{|c|}{$\mathrm{E}$} & \multicolumn{2}{|c|}{$\mathrm{D}$} & \multicolumn{2}{|c|}{ A } & \multirow{2}{*}{$\frac{\Delta_{3}}{p_{3}(\mathrm{~N} / \mathrm{mm})}$} & \multirow{2}{*}{$\frac{\Delta_{1}}{p_{1}(\mathrm{~N} / \mathrm{mm}}$} \\
\hline$\delta_{E}(\mathrm{~mm})$ & $F_{E}(\mathrm{~N})$ & $\delta_{D}(\mathrm{~mm})$ & $F_{D}(\mathrm{~N})$ & $\delta_{A}(\mathrm{~mm})$ & $F_{A}(\mathrm{~N})$ & & \\
\hline 0.41 & 1216.07 & 3.18 & 2197.54 & 16.75 & 2198.59 & 355.07 & 0.08 \\
\hline \multicolumn{8}{|c|}{ Damage } \\
\hline \multicolumn{2}{|c|}{$\mathrm{C}$} & \multicolumn{2}{|c|}{ B } & \multicolumn{2}{|c|}{ A } & $\Delta_{1}$ & $\Delta_{2}$ \\
\hline$\delta_{C}(\mathrm{~mm})$ & $F_{C}(\mathrm{~N})$ & $\delta_{B}(\mathrm{~mm})$ & $F_{B}(\mathrm{~N})$ & $\delta_{A}(\mathrm{~mm})$ & $F_{A}(\mathrm{~N})$ & $p_{1}(\mathrm{~N} / \mathrm{mm})$ & $\mathrm{p}_{2}(\mathrm{~N} / \mathrm{mm})$ \\
\hline 18.71 & 2049.6 & 18.5208 & 2205.80 & 15.5817 & 2198.60 & 2.4421 & -839.56 \\
\hline
\end{tabular}

Table 15. Identification of parameters standard-steel E24 at $\left(200^{\circ} \mathrm{C}\right.$ and $\left.1.66 \times 10^{-3} \mathrm{~s}^{-1}\right)$.

\begin{tabular}{cccccccc}
\hline & \multicolumn{3}{c}{ Hardening } & \multicolumn{3}{c}{ Damage } \\
\hline \multicolumn{3}{c}{ parameters } & & Average error & \multicolumn{2}{c}{ parameters } & Average error \\
\hline$K(\mathrm{MPa})$ & $\mathcal{E}_{0}(\%)$ & $n$ & $\xi_{F}(\%)$ & $\mathcal{E}_{s}(\%)$ & $\mathcal{E}_{u}(\%)$ & $\gamma$ & $\xi_{U}(\%)$ \\
514.137 & 1.01 & 0.2265 & 0.22 & 0.625 & 49.1 & 6.390 & 0.10 \\
\hline
\end{tabular}

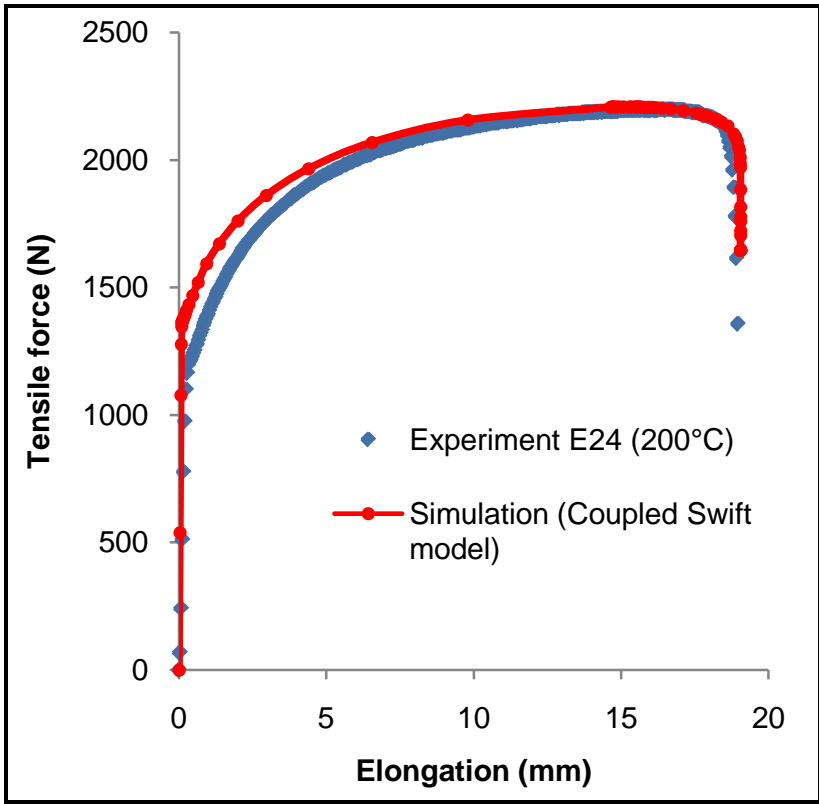

Figure 10. Tensile curve of standard-steel E24: experimental $\left(200^{\circ} \mathrm{C}\right)$ vs. simulated (with coupled Swift model). 


\subsection{Characterization of 1050 A Aluminum}

The third application is concerned with annealed 1050A aluminum. This alloy has good plastic deformation properties. Figure 11 shows the tensile curves of the reference material standard-steel E24 and that of 1050A aluminum; they exhibit a significant geometric similarity. The shape indexes obtained from the experimental tensile force/ elongation graph of 1050A aluminum presented in Table 16; they are used to determine the parameters of the coupled Swift hardening model (Table 17).

Figure 12 shows that the computed response from identified model of Table 17 and the experimental response have an average error $\xi_{F}=0.38 \%$ in the elongation range between $0.05 \mathrm{~mm}$ and $23.7 \mathrm{~mm}$ and $\xi_{U}=0.25 \%$ for elongation in the range $23.7 \mathrm{~mm}$ to $33.1 \mathrm{~mm}$.

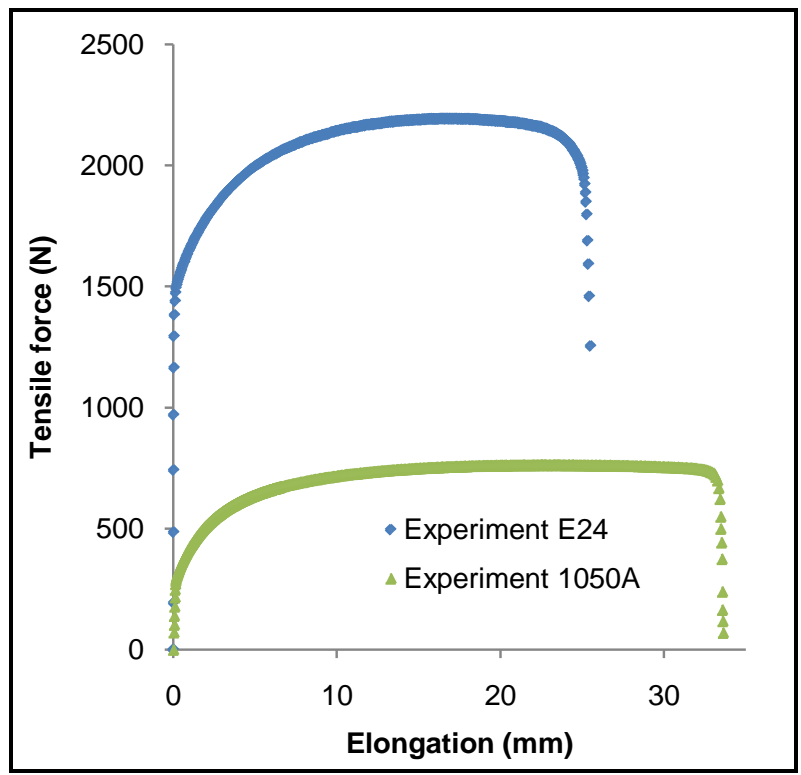

Figure 11. Similarity of the tensile graphs of standard-steel E24 and 1050A aluminum.

Table 16. Experimental shape indexes of aluminum $1050 \mathrm{~A}\left(25^{\circ} \mathrm{C} ; 1.66 \times 10^{-3} \mathrm{~s}^{-1}\right)$.

\begin{tabular}{|c|c|c|c|c|c|c|c|}
\hline \multicolumn{8}{|c|}{ Hardening } \\
\hline \multicolumn{2}{|c|}{$\mathrm{E}$} & \multicolumn{2}{|c|}{$\mathrm{D}$} & \multicolumn{2}{|c|}{ A } & \multirow{2}{*}{$\begin{array}{c}\Delta_{3} \\
p_{3}(\mathrm{~N} / \mathrm{mm})\end{array}$} & \multirow{2}{*}{$\frac{\Delta_{1}}{p_{1}(\mathrm{~N} / \mathrm{mm})}$} \\
\hline$\delta_{E}(\mathrm{~mm})$ & $F_{E}(\mathrm{~N})$ & $\delta_{D}(\mathrm{~mm})$ & $F_{D}(\mathrm{~N})$ & $\delta_{A}(\mathrm{~mm})$ & $F_{A}(\mathrm{~N})$ & & \\
\hline 0.3 & 324.83 & 2.629 & 748.10 & 22.50 & 764.29 & 181.76 & 0.815 \\
\hline \multicolumn{8}{|c|}{ Damage } \\
\hline \multicolumn{2}{|c|}{$\mathrm{C}$} & \multicolumn{2}{|c|}{ B } & \multicolumn{2}{|c|}{ A } & $\Delta_{1}$ & $\Delta_{2}$ \\
\hline$\delta_{C}(\mathrm{~mm})$ & $F_{C}(\mathrm{~N})$ & $\delta_{B}(\mathrm{~mm})$ & $F_{B}(\mathrm{~N})$ & $\delta_{A}(\mathrm{~mm})$ & $F_{A}(\mathrm{~N})$ & $p_{1}(\mathrm{~N} / \mathrm{mm})$ & $p_{2}(\mathrm{~N} / \mathrm{mm})$ \\
\hline 33.5313 & 375.3 & 33.3895 & 772.687 & 22.4987 & 764.29 & 0.771 & $-2.80 \mathrm{E}+03$ \\
\hline
\end{tabular}




\section{Conclusions}

The presented work demonstrates the possibilities available through the multiple regression method to the parameter identification problem. The procedure was proven to be efficient in determining the parameters of the Swift hardening model coupled with an isotropic damage variable.

Once the relationship between the material parameters and the shape indexes of the reference material is carried out, it will be used to identify directly the material behavior for a class of materials having the same attributes.

However the extended use of these results to other materials under different test conditions requires their behavior similarity. Hence, the materials may be grouped into equivalence classes according to the shape of their experimental response.

This method provides significant gains in computer time necessary for a complete identification procedure for the reference material. It needs very few simulations compared to other identification methods. However it just needs only one simulation for the identification of similar behavior.

Future efforts will be directed to:

1) Introduction on nondimensional variable in the analysis which will broaden the utility range of the correlations.

Table 17. Identification of parameters for aluminum $1050 \mathrm{~A}\left(25^{\circ} \mathrm{C} ; 1.66 \times 10^{-3} \mathrm{~s}^{-1}\right)$.

\begin{tabular}{cccccccc}
\hline & \multicolumn{3}{c}{ Hardening } & \multicolumn{4}{c}{ Damage } \\
\hline & Parameters & & Average error & \multicolumn{2}{c}{ Parameters } & Average error \\
\hline $\mathrm{K}(\mathrm{Mpa})$ & $\mathcal{E}_{0}(\%)$ & $n$ & $\xi_{F}(\%)$ & $\mathcal{E}_{s}(\%)$ & $\mathcal{E}_{u}(\%)$ & $\gamma$ & $\xi_{U}(\%)$ \\
151.80 & 0.038 & 0.299 & 0.38 & 0.625 & 91.82 & 6.56 & 0.25 \\
\hline
\end{tabular}

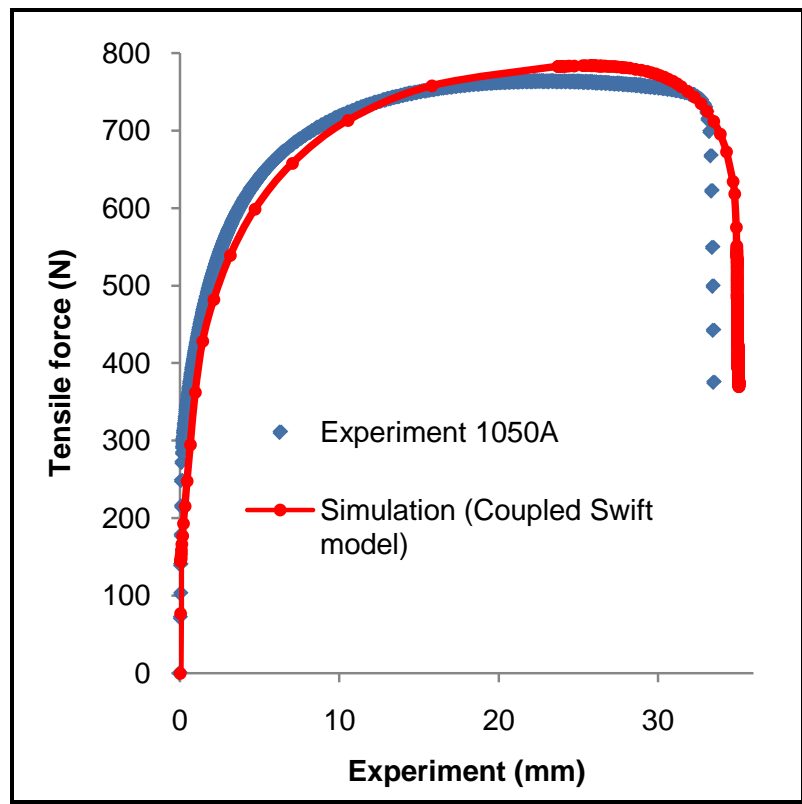

Figure 12. Tensile graphs of aluminum 1050A: Experimental vs. simulated response (coupled Swift model). 
2) Generalization to constitutive models which have a large number of parameters.

3) Sensitivity analysis of the parameter to identify with respect to the shape indexes.

\section{References}

[1] Topa, A. and Shah, Q.H. (2014) Failure Prediction in Bulk Metal Forming Process. International Journal of Manufacturing Engineering, 2014, Article ID: 385065. http://dx.doi.org/10.1155/2014/385065

[2] Jansson, T. and Nilsson, L. (2006) Minimizing the Risk of Failure in a Sheet Metal Forming Process Optimization Using Space Mapping with One-Step and Incremental Solvers. Structural and Multidisciplinary Optimization, 31, 320-332. http://dx.doi.org/10.1007/s00158-005-0604-3

[3] Pijaudier-Cabot, G. and Bazant, Z. (1987) Nonlocal Damage Theory. Journal of Engineering Mechanics, 113, 1512-1533. http://dx.doi.org/10.1061/(ASCE)0733-9399(1987)113:10(1512)

[4] Chaboche, J.L. (1988) Continuum Damage Mechanics: Part I-General Concepts. Journal of Applied Mechanics, 55, 59-64. http://dx.doi.org/10.1115/1.3173661

[5] Chaboche, J.L. (1988) Continuum Damage Mechanics: Part II-Damage Growth, Crack Initiation, and Crack Growth. Journal of Applied Mechanics, 55, 65-72. http://dx.doi.org/10.1115/1.3173662

[6] Becker, R., Needleman, A., Richmond, O. and Tvergaard, G. (1988) Void Growth and Failure in Notched Bars. Journal of the Mechanics and Physics of Solids, 36, 317-351. http://dx.doi.org/10.1016/0022-5096(88)90014-2

[7] Tvergaard, V. (1989) Material Failure by Void Growth to Coalescence. Advances in Applied Mechanics, 27, 83-151. http://dx.doi.org/10.1016/S0065-2156(08)70195-9

[8] Germain, P., Nguyen, Q.S. and Suquet, P. (1983) Continuum Thermodynamics. Journal of Applied Mechanics, 50, 1010-1020. http://dx.doi.org/10.1115/1.3167184

[9] Lemaitre, J. (1985) A Continuous Damage Mechanics Model for Ductile Fracture. Journal of Engineering Materials and Technology, 107, 83-89. http://dx.doi.org/10.1115/1.3225775

[10] Bonora, N. (1997) On the Effect of Triaxial State of Stress on Ductility Using Nonlinear CDM Model. International Journal of Fracture, 88, 359-371. http://dx.doi.org/10.1023/A:1007479522972

[11] Kachanov, L. (1958) Time of the Rupture Process under Creep Conditions. Izvestiia Akademii Nauk SSSR, Otdelenie Teckhnicheskikh Nauk, 8, 26-31.

[12] Gelin, J.C. (1998) Modelling of Damage in Metal Forming Processes. Journal of Materials Processing Technology, 80-81, 24-32. http://dx.doi.org/10.1016/S0924-0136(98)00207-6

[13] Imad, A. (2002) Sur la rupture ductile basée sur l'endommagement continu dans le cas d'un acier. Mécanique \& Industries, 3, 45-50. http://dx.doi.org/10.1016/S1296-2139(01)01132-0

[14] Andrade Pires, F.M., De Souza Neto, E.A. and Wen, D.RJ. (2004) On the Finite Element Prediction of Damage Growth and Fracture Initiation in Finitely Deforming Ductile Materials. Computer Methods in Applied Mechanics and Engineering, 193, 5223-5256. http://dx.doi.org/10.1016/j.cma.2004.01.038

[15] Teixeira, P., Santos, A.D., Andrade Pires, F.M. and César de Sá, J.M.A. (2006) Finite Element Prediction of Ductile Fracture in Sheet Metal Forming Processes. Journal of Materials Processing Technology, 177, 278-281. http://dx.doi.org/10.1016/j.jmatprotec.2006.04.059 
[16] Pereira, I.M., Rubimb, G., Acselradc, O. and Cetlin, P.R. (2008) Comparison of the Experimental and the Numerically Predicted Mechanical Damage in the Sheet Forming of Steel. Journal of Materials Processing Technology, 203, 13-18. http://dx.doi.org/10.1016/j.jmatprotec.2007.09.083

[17] Ghouati, O. and Gelin, J.C. (1998) Identification of Material Parameters Directly from Metal Forming Processes. Journal of Materials Processing Technology, 80-81, 560-564. http://dx.doi.org/10.1016/S0924-0136(98)00159-9

[18] Flores, P. (2005) Development of Experimental Equipment and Identification Procedures for Sheet Metal Constitutive Laws. PhD Thesis, University of Liege, Liege.

[19] Cooreman, S., Lecompte, D., Sol, H., Vantomme, J. and Debruyne, D. (2007) Elasto-Plastic Material Parameter Identification by Inverse Methods: Calculation of the Sensitivity Matrix. International Journal of Solids and Structures, 44, 4329-4341. http://dx.doi.org/10.1016/j.ijsolstr.2006.11.024

[20] Feng, X.-T. and Yang, C.X. (2001) Genetic Evolution of Nonlinear Material Constitutive Models. Computer Methods in Applied Mechanics and Engineering, 190, 5957-5973. http://dx.doi.org/10.1016/S0045-7825(01)00207-9

[21] Huber, N. and Tsakmakis, Ch. (2001) A Neural Network Tool for Identifying the Material Parameters of a Finite Deformation Viscoplasticity Model with Static Recovery. Computer Methods in Applied Mechanics and Engineering, 191, 353-384. http://dx.doi.org/10.1016/S0045-7825(01)00278-X

[22] Papadrakakis, M. and Lagaros, N.D. (2002) Reliability-Based Structural Optimization Using Neural Networks and Monte Carlo Simulation. Computer Methods in Applied Mechanics and Engineering, 191, 3491-3507. http://dx.doi.org/10.1016/S0045-7825(02)00287-6

[23] Nelder, J.A. and Mead, R. (1965) A Simplex Method for Function Minimization. The Computer Journal, 7, 308-313. http://dx.doi.org/10.1093/comjnl/7.4.308

[24] Ayadi, M., Cherouat, A., Slimani, F., Rezgui, M.A. and Zghal, A. (2011) Experimental and Numerical Modelling of Thermo-Forming of Anisotropic Thin Sheet. Applied Mechanics and Materials, 62, 37-48. http://dx.doi.org/10.4028/www.scientific.net/AMM.62.37

[25] Bonnet, M. and Constantinescu, A. (2005) Inverse Problems in Elasticity. Inverse Problems, 21, R1-R50. http://dx.doi.org/10.1088/0266-5611/21/2/R01

[26] Avril, S., Bonnet, M., Bretelle, A.S., Grediac, M., Hild, F., Ienny, P., Latourte, F., Lemosse, D., Pagano, S., Pagnacco, E. and Pierron, F. (2008) Overview of Identification Methods of Mechanical Parameters Based on Full-Field Measurements. Experimental Mechanics, 48, 381-402. http://dx.doi.org/10.1007/s11340-008-9148-y

[27] Ramault, C., Makris, A., Sol, H., Van Hemelrijck, D., Lecompte, D., Lamkanfi, E. and Van Paepegem, W. (2009) Development of an Inverse Method for Material Characterization Using a Biaxially Loaded Cruciform Composite Specimen. Proceedings of the SEM Annual Conference, Albuquerque, 1-4 June 2009.

[28] Ayadi, M., Rezgui, M.A., Cherouat, A., Slimani, F. and Nasri, T.M. (2009) Contribution à la modélisation expérimentale et numérique des instabilités plastiques en hydroformage des tôles minces. Mécanique \& Industries, 10, 503-518. http://dx.doi.org/10.1051/meca/2010009

[29] Cherouat, A., Ayadi, M. and Rezgui, M.A. (2011) Contribution of Strain Hardening Law Coupled to Damage and Remeshing Procedure in the Localization of Plastic Instabilities Application to Hydroforming Processes. International Journal for Computational Methods in Engineering Science and Mechanics, 12, 114-133. http://dx.doi.org/10.1080/15502287.2011.564268 
[30] Oliveira, I, Teixeira, P, Ferreira, F. and Reisa, A. (2015) Inverse Characterization of Material Constitutive Parameters for Dynamic Applications. Procedia Engineering, 114, 784-791. http://dx.doi.org/10.1016/j.proeng.2015.08.027

Submit or recommend next manuscript to SCIRP and we will provide best service for you:

Accepting pre-submission inquiries through Email, Facebook, LinkedIn, Twitter, etc. A wide selection of journals (inclusive of 9 subjects, more than 200 journals)

Providing 24-hour high-quality service

User-friendly online submission system

Fair and swift peer-review system

Efficient typesetting and proofreading procedure

Display of the result of downloads and visits, as well as the number of cited articles

Maximum dissemination of your research work

Submit your manuscript at: http://papersubmission.scirp.org/

Or contact msa@scirp.org 